Rev. Bras. Saúde Prod. Anim., Salvador, v.16, n.4, p.850-864 out../dez.., 2015 http://www.rbspa.ufba.br

\title{
Teores de óleo de linhaça para bovinos confinados: medidas corporais, carcaça e cortes cárneos
}

\section{Levels of linseed oil for feedlot cattle: body measurements, carcass and meat cuts}

\author{
ROSA, Bruna Laurindo ${ }^{1 *}$; OLIVEIRA, Emanuel Almeida de ${ }^{1}$; HENRIQUE, Wignez ${ }^{2}$; \\ PIVARO, Thiago Martins ${ }^{1}$; CARVALHO, Victor Galli ${ }^{1}$; MOTA, Diego Azevedo ${ }^{3}$; \\ PAZ, Cláudia Cristina Paro de ${ }^{4}$; ANDRADE, Antonio Tadeu de ${ }^{1}$; SAMPAIO, \\ Alexandre Amstalden Moraes ${ }^{1}$
}

\footnotetext{
${ }^{1}$ Universidade Estadual Paulista, Faculdade de Ciências Agrárias e Veterinárias, Departamento de Zootecnia, Jaboticabal, São Paulo, Brasil.

${ }^{2}$ Agência Paulista de Tecnologia dos Agronegócios, Unidade de Pesquisa e Desenvolvimento, São José do Rio Preto, São Paulo, Brasil.

${ }^{3}$ Universidade Federal dos Vales do Jequitinhonha e Mucuri, Instituto de Ciências Agrárias, Unaí, Minas Gerais, Brasil.

${ }^{4}$ Instituto de Zootecnia/Agência Paulista de Tecnologia dos Agronegócios, Sertãozinho, São Paulo, Brasil.

*Endereço para correspondência: brunaarosa@hotmail.com
}

\section{RESUMO}

Os objetivos foram avaliar dietas contendo teores de óleo de linhaça in natura $(1,0 ; 3,8 \mathrm{e}$ $5,2 \%$ da MS da dieta) sobre as características da carcaça e cortes cárneos, e correlacionar esses resultados com medidas corporais in vivo de 14 fêmeas e 15 machos castrados Nelore $x$ Canchim. Os animais foram confinados individualmente recebendo $20 \%$ de cana-deaçúcar como volumoso e $80 \%$ de concentrado, em um delineamento de blocos ao acaso (teores de óleo x condição sexual). Todos os animais de cada bloco foram abatidos quando o peso corporal médio atingiu $500 \mathrm{~kg}$. Não foram observadas interações entre os fatores estudados. Acrescentar até $5,2 \%$ de óleo de linhaça in natura da dieta de bovinos cruzados aumenta o peso dos principais cortes cárneos da carcaça, reduz as perdas no resfriamento e não altera o teor de gordura renal-pélvica-inguinal. Fêmeas e machos castrados Nelore x Canchim produzem quantidades similares de carne do traseiro especial, em peso e rendimento. Juntamente com o peso corporal, a medida do contorno pelviano é a mais indicada para auxiliar na formação de lotes homogêneos para o abate ou experimentação, por apresentar as melhores correlações com as características utilizadas na comercialização brasileira de carne, como peso e rendimento da carcaça.

Palavras-chave: correlação, cortes nobres, fêmeas, machos castrados, medidas biométricas

\section{SUMMARY}

The objectives were to evaluate diets containing levels of in natura linseed oil (1.0, 3.8 and 5.2\% of diet DM) on carcass characteristics and meat cuts, and correlate these results with in vivo body measures of 14 heifers and 15 steers Nellore x Canchim. The animals were confined individually receiving $20 \%$ of sugar cane as roughage and $80 \%$ concentrate, in a complete randomized block (oil content $\mathrm{x}$ sexual condition). All animals of each block were slaughtered when the average body weight reached $500 \mathrm{~kg}$. No interactions between treatments were observed. Add up to $5.2 \%$ of linseed oil in diet of crossbred cattle increases the weight of the main carcass cuts, reduce the loss during cooling and does not change the level of renal pelvic-inguinal fat. Heifers and steers Nellore $\mathrm{x}$ Canchim produce similar amounts of weight and yield hindquarter's meat. Along with body weight, the extent pelviano contour is the most indicated to assist the formation of homogeneous lots for slaughter or trial, because showed the best correlation with the characteristics used in the Brazilian market of meat, such as weight and carcass yield.

Key-words: biometric measurements, correlation, heifers, prime cuts, steers 


\section{INTRODUÇ̃̃̃O}

A produção brasileira de carne bovina tem avançado nas últimas décadas, possibilitando ao Brasil exportar para mais de 140 países e estar entre os maiores produtores dessa commodity (CNA, 2013). De acordo com o Ministério da Agricultura, Pecuária e Abastecimento (MAPA, 2013), nos próximos dez anos deverão ser produzidos mais 9,3 milhões de toneladas de equivalente carcaça, um aumento de $35 \%$ em relação ao ano de 2012 , podendo refletir no crescimento das exportações da carne bovina brasileira pelo mundo.

Muitos fatores se complementam na produção de carcaças com cortes cárneos padronizados e de qualidade, como a genética, idade, alimentação e condição sexual. A inclusão de óleos vegetais na alimentação de bovinos confinados eleva a concentração energética da dieta e pode melhorar as características da carcaça. Diversos trabalhos avaliaram fontes e teores de óleo in natura na dieta de ruminantes em relação às características da carcaça, porém os resultados observados ainda são contraditórios. Bhatt et al. (2011) não observaram diferenças com a inclusão de óleo de coco na dieta de ovinos, diferentemente do observado por Vander Pol et al. (2009) que, trabalhando com novilhas, observaram uma melhora nos efeitos sobre a carcaça com a inclusão de diferentes teores de óleo de milho.

Independentemente do custo do óleo de linhaça, sua utilização na alimentação animal pode se tornar interessante por possuir propriedades muito benéficas para os seres humanos quanto à sua composição em ácidos graxos, principalmente os da família $\omega 3$ (MARTIN et al., 2006). Conhecer os efeitos de diferentes quantidades desse óleo na dieta de bovinos quanto às possíveis alterações nas características da carcaça e rendimento dos cortes cárneos torna-se importante.

Outra ferramenta que pode ser utilizada no sistema de produção com o intuito de auxiliar na formação dos lotes mais homogêneos são as medidas corporais, por permitirem, segundo Fisher (1975), conhecer o desenvolvimento das partes que compõem o corpo dos animais. Estudos de mensurações biométricas e suas relações com características de carcaça e/ou cortes cárneos de bovinos ainda são escassos na literatura, e tem a vantagem de não ser um método invasivo.

Diante destas observações, objetivou-se avaliar teores de óleo de linhaça na dieta de bovinos Nelore x Canchim, fêmeas e machos castrados, sobre as características da carcaça e rendimento dos cortes cárneos e suas relações com medidas corporais realizadas in vivo.

\section{MATERIAL E MÉTODOS}

Todos os procedimentos experimentais foram submetidos à prévia apreciação pela Comissão de Ética e Bem Estar Animal da Faculdade de Ciências Agrárias e Veterinárias (FCAV) e receberam aprovação através do processo $n^{0} 20.541 / 10$. O experimento foi desenvolvido na FCAV/Unesp, Campus de Jaboticabal, SP, Brasil, nos períodos de abril a setembro de 2012 . Foram utilizados 15 machos castrados e 14 fêmeas Nelore x Canchim, com idade inicial de $24 \pm 2$ meses, com pesos médios inicias de 427,8 e 400,6 $\mathrm{kg}$, respectivamente, provenientes do mesmo rebanho. A castração dos machos foi efetuada por volta dos 15 meses de idade com uso de castrador modelo burdizzo.

Os animais foram recriados no pasto e receberam suplementação concentrada no período de seca que antecedeu o 
Rev. Bras. Saúde Prod. Anim., Salvador, v.16, n.4, p.850-864 out../dez.., 2015 http://www.rbspa.ufba.br ISSN 15199940

experimento. Chegado o período de adaptação, estes foram colocados em baias individuais, cobertas e concretadas, e adaptados às instalações e ao manejo por 28 dias. Nesse período, a dieta foi composta por cana-de-açúcar e concentrado (farelo de soja, milho e núcleo mineral) e a quantidade de volumoso, incialmente compondo $60 \%$ da matéria seca (MS) da dieta, foi diminuindo 10 unidades percentuais a cada semana.

Para iniciar o período experimental, os animais foram separados em blocos, considerando-se o peso corporal e a condição sexual. As dietas e o posicionamento dos blocos, cinco no total, foram distribuídos aleatoriamente, tendo o tratamento com o teor de $1,0 \%$ de óleo e fêmea uma repetição a menos do que os demais.

Foram formuladas três dietas pelo programa RLM ${ }^{\circledR}$ (LANNA et al., 1999), com teores crescentes de óleo de linhaça in natura não refinado $(1,0 ; 3,8$ e 5,2\% da MS), adquirido comercialmente. Como volumoso exclusivo foi utilizado a canade-açúcar variedade forrageira IAC 862480, colhida e picada diariamente.

As dietas experimentais apresentaram relação volumoso:concentrado de 20:80, base na MS. A porcentagem dos ingredientes e a composição químicobromatológica das dietas experimentais estão apresentadas na Tabela 1.

Tabela 1. Composição percentual e características nutricionais das dietas experimentais

\begin{tabular}{|c|c|c|c|}
\hline \multirow{2}{*}{ Ingrediente/Fração } & \multicolumn{3}{|c|}{ Dieta - Teor de óleo de linhaça (\% da MS) } \\
\hline & 1,0 & 3,8 & 5,2 \\
\hline \multicolumn{4}{|l|}{ Composição percentual (\% da MS) } \\
\hline Cana-de-açúcar & 20,0 & 20,0 & 20,0 \\
\hline Milho em grão moído & 50,0 & 47,0 & 44,0 \\
\hline Farelo de soja & 2,0 & 3,0 & 2,2 \\
\hline Farelo de glúten de milho & 23,0 & 22,2 & 24,6 \\
\hline Ureia & 1,0 & 1,0 & 1,0 \\
\hline Óleo de linhaça & 1,0 & 3,8 & 5,2 \\
\hline Núcleo mineral $^{1}$ & 2,0 & 2,0 & 2,0 \\
\hline Óxido de magnésio & 0,4 & 0,4 & 0,4 \\
\hline Bicarbonato de sódio & 0,6 & 0,6 & 0,6 \\
\hline \multicolumn{4}{|l|}{ Características nutricionais } \\
\hline Matéria $\operatorname{seca}^{2}(\%)$ & 76,27 & 76,29 & 75,65 \\
\hline Proteína bruta ${ }^{2}(\%$ na MS $)$ & 13,77 & 14,87 & 14,03 \\
\hline Extrato etéreo $^{2}(\%$ na MS $)$ & 4,68 & 6,99 & 7,86 \\
\hline Fibra em detergente neutro ${ }^{2}(\%$ na MS) & 33,63 & 31,38 & 33,11 \\
\hline Nutrientes digestíveis totais ${ }^{3}(\%$ na MS) & 77,12 & 80,65 & 81,96 \\
\hline
\end{tabular}

${ }^{1}$ Composição por kg do produto: fósforo $=40 \mathrm{~g}$; cálcio $=146 \mathrm{~g}$; sódio $=56 \mathrm{~g}$; enxofre $=40 \mathrm{~g}$; magnésio $=$ $20 \mathrm{~g} ;$ cobre $=350 \mathrm{~g} ;$ zinco $=1.300 \mathrm{mg}$; manganês $=900 \mathrm{mg}$; ferro $=1.050 \mathrm{mg}$; cobalto $=10 \mathrm{mg}$; iodo $=$ $24 \mathrm{mg}$; selênio $=10 \mathrm{mg}$; flúor $=400 \mathrm{mg} ;{ }^{2}$ Determinados em laboratório; ${ }^{3}$ Estimados pelo $\mathrm{RLM}^{\circledR}$ (LANA et al., 1999).

As refeições foram fornecidas diariamente às $8 \mathrm{~h}$ e às $15 \mathrm{~h}$, na forma de ração completa, sendo o óleo adicionado e misturado ao concentrado diária e individualmente, e este misturado ao volumoso no cocho. A quantidade de alimentos ofertada foi dividida igualmente entre os horários e permitiu sobras aproximadamente de $12 \%$ da MS ingerida no dia anterior.

Os animais foram pesados no início, a cada 28 dias e no final do confinamento, precedidos de jejum total por 15 horas. Em conjunto com a pesagem final foram 
realizadas as mensurações biométricas das alturas da garupa, cernelha e tórax; larguras do tórax, ísquios e garupa; perímetro torácico e contorno pelviano (SAMPAIO, 1990), todas obtidas com o auxílio de fita métrica padrão, segundo recomendações de Cyrillo et al. (2001), e bengala zoométrica.

Foi estipulado em $500 \mathrm{~kg}$ o peso médio corporal dos animais de cada bloco para o abate. Assim, os animais foram abatidos em abatedouro comercial de forma escalonada, por bloco, sendo dois blocos abatidos após 96 dias de período experimental, outros dois após 110 e um após 138 dias. No abate foram obtidos os valores de $\mathrm{pH}$, temperatura, comprimento (distância da borda cranial da primeira costela em seu ponto médio até o bordo anterior da sínfise ísquio pubiana) e profundidade (distância do bordo anterior da cartilagem externa até a borda inferior do canal medular entre a 5- e 6- vértebras dorsais) da carcaça quente, e os pesos da gordura renalpélvica-inguinal, fígado e rins.

Após 24 horas de resfriamento em câmara frigorífica, foi obtido o peso frio das carcaças e calculadas as perdas no resfriamento. Em seguida, foram feitas as divisões das meias-carcaças em traseiro e dianteiro, separada entre as 5e 6 - vértebras torácicas, e do traseiro, a uma distância de $20 \mathrm{~cm}$ da coluna vertebral, foi retirada a ponta de agulha, resultando no traseiro especial. Os cortes primários foram pesados para $\mathrm{o}$ cálculo de rendimento em relação à carcaça resfriada.

Das meias-carcaças esquerdas foram retiradas peças do Longissimus com ossos entre as 6- e 13- costelas e congeladas. No laboratório, cada peça foi separada entre a $12^{-}-$e $13 \stackrel{a}{-}$ costelas e determinada a área de olho de lombo (AOL), por decalque do perímetro do músculo em papel vegetal, posteriormente digitalizado e medido por meio do programa Autocad (AUTO
COMPUTER AIDED DESIGN. AUTODESK, INC). Das meias-carcaças direitas, foram retirados os seguintes cortes cárneos: alcatra completa (alcatra + picanha + maminha), contrafilé, filé mignon, músculo do traseiro, coxão mole, coxão duro, lagarto, patinho, acém, peixinho, paleta, músculo do dianteiro, cupim, ponta de peito e pescoço. Os cortes foram pesados e calculados seus rendimentos em relação à meia-carcaça. Os pesos dos cortes do traseiro especial (alcatra completa + contrafilé + filé mignon + músculo + coxão mole + coxão duro + lagarto + patinho), exceto o coxão duro e músculo, foram somados $\mathrm{e}$ classificados como carne de primeira; todos os cortes do dianteiro (acém + peixinho + paleta + músculo + cupim + ponta de peito + pescoço), o coxão duro e o músculo do traseiro foram somados e classificados como carne de segunda; a alcatra completa, contrafilé e filé mignon foram somados e classificados como cortes nobres (PAZDIORA, 2011). A alcatra completa, contrafilé, cupim, ponta de peito e ponta de agulha foram somados e classificados como carne para churrasco (TULLIO, 2004).

Para cada variável estudada, foi verificada a normalidade da distribuição das variâncias pelo teste de ShapiroWilk, considerando-se probabilidade de 0,05 como significativa, e os dados transformados, caso houvesse indicação (SAS, 2009). O delineamento experimental foi em blocos incompletos ao acaso, em esquema fatorial $3 \times 2$ (teores de óleo e condição sexual), e 29 unidades experimentais, sendo que o tratamento com $1,0 \%$ de óleo e fêmea teve uma repetição a menos. $\mathrm{O}$ modelo de análise incluiu o peso inicial como covariável, os blocos como efeito aleatório, os teores de óleo e condição sexual como efeitos fixos e a interação entre eles, sendo analisados pelo procedimento MIXED (SAS, 2009). As características de carcaça e os cortes 
cárneos foram analisados em função dos teores de óleo de linhaça por meio de análises de regressão pelo PROC GLM (SAS, 2009), sendo considerada como significativa probabilidade igual ou inferior a 0,10 . Os efeitos de sexo e bloco foram incluídos no modelo como efeitos classificatórios e o efeito de bloco foi considerado como aleatório.

As medidas corporais e o peso final dos animais, as características da carcaça e os cortes cárneos classificados foram submetidos à análise de correlação de Pearson, pelo procedimento CORR (SAS, 2009), considerando-se as probabilidades de 0,01 e 0,05 como significativas.

\section{RESULTADOS E DISCUSSÃO}

Não foram observadas interações entre os teores de óleo e condições sexuais para as variáveis estudadas.

O peso da carcaça quente foi maior para os machos castrados $(302,14 \pm 25,73$ $\mathrm{kg})$ em relação às fêmeas $(287,45 \pm$ $16,06 \mathrm{~kg}$ ), sem diferenças entre as dietas; já o rendimento da carcaça quente não diferiu entre os teores de óleo e as condições sexuais, com média de $56,45 \pm 2,86 \%$ (ROSA, 2014).

Foram observados aumentos lineares da temperatura da carcaça e da AOL em $\mathrm{cm}^{2}$ e em $\mathrm{cm}^{2} / 100 \mathrm{~kg}$ de carcaça, e redução das perdas no resfriamento com o aumento da quantidade de óleo de linhaça in natura na MS da dieta (Tabela 2). A espessura de gordura de cobertura diferiu $(\mathrm{P}<0,05)$ entre as dietas $(9,26 \pm 7,33 \mathrm{~mm} ; 9,82 \pm 2,58 \mathrm{~mm}$ e $12,05 \pm 3,51 \mathrm{~mm}$ para 1,$0 ; 3,8$ e $5,2 \%$ de óleo de linhaça, respectivamente) e entre as condições sexuais $(8,58 \pm 3,54$ $\mathrm{mm}$ e $12,17 \pm 5,64 \mathrm{~mm}$, para machos castrados e fêmeas, respectivamente) (ROSA, 2014), atuando como isolante térmico e contribuindo para a persistência da temperatura das carcaças bovinas, assim como para as reduções das perdas no resfriamento que ficaram abaixo de 2,0\%. Valores de perdas no resfriamento abaixo desse percentual são indicativos de carcaças com bom acabamento de gordura, pois quanto maior a espessura de gordura de cobertura menor as perdas por gotejamento no momento em que as carcaças são resfriadas (FELÍCIO, 2011).

Com relação à AOL, o aumento do teor energético das dietas implicou em maior deposição de massa muscular nas carcaças bovinas (Tabela 2), apesar de ter ocorrido redução linear da quantidade ingerida de MS pelos animais, tanto em $\mathrm{kg} /$ dia quanto em porcentagem do peso corporal (ROSA, 2014). O acréscimo da quantidade de carne na carcaça foi possível devido aos animais não estarem na idade adulta a qual, por definição de Owens et al. (1995), é quando o animal atinge a máxima deposição de matéria desengordurada (soma de água, proteína e minerais), ou seja, quando o ganho de peso passa a ser composto exclusivamente por gordura. Maiores AOL nas carcaças podem implicar em maior remuneração nas relações de compra e venda tanto para produtores quanto para os frigoríficos, pela correlação positiva da AOL com o peso da carcaça quente (YOKOO et al., 2008). $\mathrm{O}$ pH e o peso da ponta de agulha apresentaram efeito quadrático $(\mathrm{P}<0,10)$ com o aumento dos teores de óleo de linhaça na dieta (Tabela 2). De acordo com Lawrie (2005), o pH por ser influenciado por diversos fatores como estresse no transporte e pré-abate, sendo, portanto, um atributo intrínseco do animal. No presente estudo, os valores de $\mathrm{pH}$ ficaram acima dos 5,8 considerados normais para a carne bovina logo após o abate (LAWRIE, 2005). 
Tabela 2. Características da carcaça quente e fria, e dos componentes não-carcaça de fêmeas e machos castrados Nelore x Canchim, terminados em confinamento e alimentados com teores crescentes de óleo de linhaça

\begin{tabular}{|c|c|c|c|c|c|c|c|c|c|c|}
\hline \multirow[b]{2}{*}{ Variáveis } & \multirow{2}{*}{$\begin{array}{c}\mathrm{P}^{2} \\
\text { Interação }\end{array}$} & \multicolumn{3}{|c|}{ Teor de óleo (\% da MS) } & \multicolumn{2}{|c|}{ P Regressão } & \multicolumn{2}{|c|}{ Condição sexual } & \multirow[b]{2}{*}{$\mathrm{P}$} & \multirow[b]{2}{*}{$\mathrm{EP}^{3}$} \\
\hline & & 1,0 & 3,8 & 5,2 & Linear & Quadrática & $\begin{array}{l}\text { Machos } \\
\text { castrados }\end{array}$ & Fêmeas & & \\
\hline \multicolumn{11}{|l|}{ Carcaça quente } \\
\hline $\mathrm{pH}$ & 0,6151 & 6,19 & 6,35 & 6,22 & 0,7883 & 0,0942 & 6,31 & 6,20 & 0,4028 & 0,045 \\
\hline Temperatura, ${ }^{\circ} \mathrm{C}$ & 0,4998 & 38,79 & 39,32 & 39,73 & 0,0657 & 0,8890 & 39,12 & 39,44 & 0,5669 & 0,215 \\
\hline Comprimento, $\mathrm{cm}$ & 0,6104 & 131,27 & 131,13 & 131,99 & 0,6116 & 0,6698 & 131,64 & 131,29 & 0,8035 & 0,698 \\
\hline Profundidade, $\mathrm{cm}$ & 0,7936 & 67,22 & 67,29 & 65,81 & 0,2370 & 0,4575 & 68,17 & 65,38 & 0,0320 & 0,490 \\
\hline \multicolumn{11}{|l|}{ Carcaça fria } \\
\hline Área de olho de lombo, $\mathrm{cm}^{2}$ & 0,9351 & 75,12 & 80,04 & 86,06 & 0,0122 & 0,8658 & 82,18 & 78,64 & 0,3068 & 2,074 \\
\hline Área de olho de lombo 100 & 0,9636 & 26,39 & 27,52 & 29,00 & 0,0309 & 0,8541 & 27,57 & 27,71 & 0,8835 & 0,439 \\
\hline Perdas no resfriamento, $\%$ & 0,2053 & 1,80 & 1,22 & 1,18 & 0,0094 & 0,1348 & 1,38 & 1,42 & 0,8632 & 0,106 \\
\hline \multicolumn{11}{|l|}{ Pesos, $\mathrm{kg}$} \\
\hline Total & 0,7196 & 286,04 & 295,74 & 296,78 & 0,1106 & 0,4527 & 302,14 & 283,41 & 0,0152 & 4,516 \\
\hline Dianteiro & 0,6817 & 106,83 & 110,83 & 110,58 & 0,1818 & 0,3847 & 114,87 & 103,96 & 0,0025 & 2,109 \\
\hline Traseiro especial & 0,7975 & 131,16 & 134,48 & 136,32 & 0,1464 & 0,8081 & 136,86 & 131,11 & 0,1069 & 1,992 \\
\hline Ponta de agulha & 0,9555 & 47,83 & 50,78 & 49,83 & 0,1010 & 0,0789 & 50,86 & 48,10 & 0,2543 & 0,753 \\
\hline \multicolumn{11}{|l|}{ Rendimentos, $\%$} \\
\hline Dianteiro & 0,9117 & 37,26 & 37,45 & 37,19 & 0,8737 & 0,5868 & 37,99 & 36,61 & 0,0090 & 0,225 \\
\hline Traseiro especial & 0,9464 & 45,85 & 45,42 & 45,96 & 0,8433 & 0,2828 & 45,21 & 46,28 & 0,0397 & 0,210 \\
\hline Ponta de agulha & 0,9422 & 16,85 & 17,13 & 16,87 & 0,9566 & 0,3412 & 16,78 & 17,12 & 0,4705 & 0,167 \\
\hline \multicolumn{11}{|l|}{ Componentes não-carcaça, kg } \\
\hline Gordura renal-pélvica-inguinal & 0,9225 & 9,97 & 11,70 & 11,64 & 0,1472 & 0,3415 & 10,26 & 11,95 & 0,1067 & 0,440 \\
\hline Fígado & 0,2363 & 5,94 & 5,78 & 5,65 & 0,1823 & 0,9208 & 6,13 & 5,45 & 0,0249 & 0,124 \\
\hline Rins & 0,1619 & 0,94 & 0,96 & 1,00 & 0,1640 & 0,6251 & 0,96 & 0,98 & 0,7241 & 0,023 \\
\hline
\end{tabular}

${ }^{1} \mathrm{~cm}^{2} / 100 \mathrm{~kg}$ de carcaça; ${ }^{2}$ Probabilidade; ${ }^{3}$ Erro padrão 
O uso do óleo de linhaça não alterou $(\mathrm{P}>0,10)$ o conteúdo de gordura renalpélvica-inguinal na carcaça dos bovinos cruzados, independentemente do teor utilizado (Tabela 2) e mostrando a eficiência de tal suplementação. Esse acúmulo de gordura pode reduzir o rendimento da carcaça e o lucro de quem a produziu, pois o produtor não receberia por essa gordura. A gordura pode ser estocada nas formas subcutânea, intermuscular, intramuscular e interna (pélvica, renal e inguinal), mas, a composição e a quantidade desses depósitos dependerão da dieta $\mathrm{e}$ necessidade do uso dessas reservas no decorrer da vida do animal (ENGLE et al., 2000). Segundo Geay et al. (2001), a quantidade e a composição dos lipídios armazenados nos tecidos dependem, além das dietas, do metabolismo hepático, dos processos de digestão e absorção intestinal, e dos sistemas de transporte.

Os pesos dos cortes da paleta, alcatra completa, contrafilé e coxão mole foram crescentes com o aumento dos teores de óleo de linhaça na dieta, sendo também observado efeito quadrático para $\mathrm{o}$ cupim e coxão duro (Tabela 3 ).

Não foram observadas diferenças entre as dietas para os cortes acém, peixinho, músculos do dianteiro e traseiro, ponta de peito, pescoço, filé mignon, lagarto e patinho, mas quando somados os cortes classificados como carne de segunda, nobres, para churrasco e total, constatouse que eles aumentaram com a maior adição de óleo de linhaça na dieta (Tabela 3). O aumento de peso dos cortes cárneos, principalmente os do traseiro especial, nobres e para churrasco atende às exigências dos frigoríficos (Tabela 3 ). Segundo Pascoal et al. (2011), os frigoríficos têm priorizado a venda de carne desossada e embalada a vácuo pela agregação de valor e, dentre esses cortes, os considerados como de primeira, nobres e os de churrasco são os mais rentáveis na comercialização.

Quanto aos rendimentos dos cortes cárneos, apenas a porcentagem do total de carne foi ascendente com o aumento dos teores de óleo de linhaça na dieta, com efeito quadrático para o rendimento do cupim (Tabela 4).

Machos castrados obtiveram carcaças mais pesadas em relação às fêmeas (Tabela 2), e essas carcaças são preferidas pelos frigoríficos, por demandar a mesma mão-de-obra e tempo de processamento do que carcaças mais leves (SILVA et al., 2008). Os maiores peso e rendimento do dianteiro, profundidade de carcaça (Tabela 2) e pesos do acém, peixinho, paleta e músculo (Tabela 3) dos machos castrados, estão relacionados com as características de diferenciação sexual, pois, apesar dos animais terem sido castrados aos 15 meses, pode-se observar efeito dessa diferenciação ocasionada, provavelmente, por ação dos hormônios andrógenos que são associados à maior deposição de massa muscular no organismo (McDONALD \& PINEDA, 1991). Além disso, os machos castrados tiveram fígados mais pesados, justificados pela maior taxa de deposição de massa corporal, o que pode exigir do fígado maior demanda de síntese de nutrientes para formação de tecidos (KUSS et al., 2007).

Machos castrados e fêmeas Nelore $\mathrm{x}$ Canchim produzem quantidades similares de cortes cárneos do traseiro especial, tanto em peso quanto em rendimento (Tabela 3), semelhantes aos resultados de Coutinho Filho et al. (2006). Mesmo as fêmeas produzindo carcaças mais leves não diferiram quanto ao conteúdo do traseiro especial e de seus cortes cárneos, com pesos similares aos dos machos castrados. 
Tabela 3. Peso e classificação dos cortes do dianteiro e traseiro especial da meia-carcaça direita de fêmeas e machos castrados Nelore $\mathrm{x}$ Canchim, terminados em confinamento e alimentados com teores crescentes de óleo de linhaça

\begin{tabular}{|c|c|c|c|c|c|c|c|c|c|c|}
\hline \multirow[b]{2}{*}{ Variáveis (kg) } & \multirow{2}{*}{$\begin{array}{c}\mathrm{P}^{6} \\
\text { Interação }\end{array}$} & \multicolumn{3}{|c|}{ Teor de óleo (\% da MS) } & \multicolumn{2}{|c|}{ P Regressão } & \multicolumn{2}{|c|}{ Condição sexual } & \multirow[b]{2}{*}{$\mathrm{P}$} & \multirow[b]{2}{*}{$\mathrm{EP}^{7}$} \\
\hline & & 1,0 & 3,8 & 5,2 & Linear & Quadrática & $\begin{array}{c}\text { Machos } \\
\text { castrados }\end{array}$ & Fêmeas & & \\
\hline \multicolumn{11}{|l|}{ Cortes do dianteiro } \\
\hline Acém & 0,6036 & 8,14 & 8,45 & 8,68 & 0,1314 & 0,8983 & 8,92 & 7,93 & 0,0138 & 0,225 \\
\hline Peixinho & 0,8650 & 1,47 & 1,40 & 1,45 & 0,7624 & 0,1582 & 1,54 & 1,34 & 0,0028 & 0,032 \\
\hline Paleta & 0,8822 & 8,37 & 8,57 & 8,88 & 0,0230 & 0,7265 & 9,09 & 8,12 & 0,0021 & 0,214 \\
\hline Músculo & 0,2996 & 6,65 & 7,04 & 6,76 & 0,7354 & 0,2192 & 7,21 & 6,42 & 0,0176 & 0,189 \\
\hline Cupim & 0,9172 & 2,58 & 3,08 & 2,95 & 0,0632 & 0,0517 & 2,96 & 2,78 & 0,3654 & 0,082 \\
\hline Ponta de peito & 0,8594 & 6,24 & 6,50 & 6,65 & 0,2206 & 0,8179 & 6,63 & 6,30 & 0,3493 & 0,145 \\
\hline Pescoço & 0,7540 & 7,34 & 7,09 & 7,20 & 0,7691 & 0,6345 & 7,35 & 7,07 & 0,4968 & 0,188 \\
\hline \multicolumn{11}{|l|}{ Cortes do traseiro } \\
\hline Alcatra completa ${ }^{1}$ & 0,7330 & 8,14 & 8,37 & 8,52 & 0,0842 & 0,9768 & 8,21 & 8,48 & 0,1394 & 0,130 \\
\hline Contrafilé & 0,6050 & 9,11 & 9,35 & 9,59 & 0,0910 & 0,9887 & 9,78 & 8,92 & 0,2873 & 0,207 \\
\hline Filé mignon & 0,5036 & 2,62 & 2,55 & 2,61 & 0,9109 & 0,4897 & 2,62 & 2,56 & 0,8466 & 0,076 \\
\hline Músculo & 0,5580 & 4,74 & 4,88 & 4,85 & 0,4305 & 0,4355 & 4,93 & 4,72 & 0,1073 & 0,098 \\
\hline Coxão mole & 0,8331 & 9,64 & 10,08 & 10,18 & 0,0580 & 0,4555 & 10,08 & 9,86 & 0,4186 & 0,155 \\
\hline Coxão duro & 0,9072 & 5,11 & 5,60 & 5,50 & 0,0336 & 0,0663 & 5,53 & 5,28 & 0,2626 & 0,102 \\
\hline Lagarto & 0,9940 & 2,56 & 2,65 & 2,63 & 0,5725 & 0,5936 & 2,57 & 2,65 & 0,5999 & 0,056 \\
\hline Patinho & 0,7990 & 5,42 & 5,31 & 5,55 & 0,4256 & 0,2115 & 5,48 & 5,37 & 0,4317 & 0,109 \\
\hline \multicolumn{11}{|l|}{ Classificação } \\
\hline Primeira $^{2}$ & 0,9235 & 37,51 & 38,05 & 39,11 & 0,1305 & 0,7622 & 38,52 & 37,93 & 0,6608 & 0,556 \\
\hline Segunda ${ }^{3}$ & 0,6656 & 50,64 & 52,49 & 52,90 & 0,0712 & 0,4732 & 54,05 & 49,98 & 0,0034 & 0,995 \\
\hline Nobres ${ }^{4}$ & 0,9109 & 19,80 & 20,01 & 20,81 & 0,0614 & 0,4791 & 20,27 & 20,14 & 0,9113 & 0,330 \\
\hline Churrasco $^{5}$ & 0,9625 & 49,94 & 52,07 & 52,93 & 0,0193 & 0,5042 & 52,13 & 51,17 & 0,6516 & 0,765 \\
\hline Total & 0,7354 & 111,98 & 115,57 & 117,17 & 0,0364 & 0,6028 & 117,42 & 112,40 & 0,1445 & 1,797 \\
\hline
\end{tabular}

${ }^{1}$ Alcatra + picanha + maminha; ${ }^{2}$ Todos os cortes do traseiro, exceto músculo e coxão duro $;{ }^{3}$ Todos os cortes do dianteiro + músculo do traseiro + coxão duro; ${ }^{4}$ Alcatra completa + contrafilé + filé mignon; ${ }^{5}$ Alcatra completa + contrafilé + ponta de peito + cupim + ponta de agulha; ${ }^{6}$ Probabilidade $;{ }^{7}$ Erro padrão 
Tabela 4. Rendimento e classificação dos cortes cárneos da meia-carcaça direita de fêmeas e machos castrados Nelore x Canchim, terminados em confinamento e alimentados com teores crescentes de óleo de linhaça

\begin{tabular}{|c|c|c|c|c|c|c|c|c|c|c|}
\hline \multirow[b]{2}{*}{ Variáveis (\%) } & \multirow{2}{*}{$\begin{array}{c}\mathrm{P}^{6} \\
\text { Interação }\end{array}$} & \multicolumn{3}{|c|}{ Teor de óleo (\% da MS) } & \multicolumn{2}{|c|}{ P Regressão } & \multicolumn{2}{|c|}{ Condição sexual } & \multirow[b]{2}{*}{$\mathrm{P}$} & \multirow[b]{2}{*}{$\mathrm{EP}^{7}$} \\
\hline & & 1,0 & 3,8 & 5,2 & Linear & Quadrática & $\begin{array}{l}\text { Machos } \\
\text { castrados }\end{array}$ & Fêmeas & & \\
\hline \multicolumn{11}{|l|}{ Cortes do dianteiro } \\
\hline Acém & 0,7226 & 5,65 & 5,71 & 5,76 & 0,5554 & 0,9586 & 5,91 & 5,50 & 0,0865 & 0,088 \\
\hline Peixinho & 0,6918 & 1,02 & 0,95 & 0,97 & 0,1710 & 0,1696 & 1,02 & 0,94 & 0,0289 & 0,015 \\
\hline Paleta & 0,9739 & 5,81 & 5,79 & 5,89 & 0,5264 & 0,6028 & 6,03 & 5,63 & 0,0241 & 0,070 \\
\hline Músculo & 0,4102 & 4,61 & 4,76 & 4,48 & 0,5245 & 0,2226 & 4,77 & 4,46 & 0,1095 & 0,086 \\
\hline Cupim & 0,9991 & 1,81 & 2,11 & 1,96 & 0,2214 & 0,0532 & 1,99 & 1,93 & 0,7234 & 0,058 \\
\hline Ponta de peito & 0,6446 & 4,33 & 4,42 & 4,44 & 0,5838 & 0,8259 & 4,40 & 4,39 & 0,9453 & 0,079 \\
\hline Pescoço & 0,7627 & 5,09 & 4,80 & 4,81 & 0,3580 & 0,5268 & 4,88 & 4,92 & 0,8550 & 0,108 \\
\hline \multicolumn{11}{|l|}{ Cortes do traseiro } \\
\hline Alcatra completa ${ }^{1}$ & 0,3139 & 5,66 & 5,68 & 5,69 & 0,8122 & 0,9455 & 5,45 & 5,91 & 0,0038 & 0,062 \\
\hline Contrafilé & 0,7733 & 6,32 & 6,20 & 6,47 & 0,4266 & 0,2123 & 6,31 & 6,36 & 0,9139 & 0,147 \\
\hline Filé mignon & 0,6060 & 1,83 & 1,75 & 1,74 & 0,1013 & 0,3671 & 1,76 & 1,79 & 0,8701 & 0,061 \\
\hline Músculo & 0,6176 & 3,29 & 3,30 & 3,22 & 0,4218 & 0,5023 & 3,27 & 3,28 & 0,8847 & 0,031 \\
\hline Coxão mole & 0,8011 & 6,72 & 6,85 & 6,79 & 0,6283 & 0,4309 & 6,69 & 6,88 & 0,3589 & 0,069 \\
\hline Coxão duro & 0,6578 & 3,54 & 3,71 & 3,66 & 0,3144 & 0,2737 & 5,59 & 3,69 & 0,3702 & 0,044 \\
\hline Lagarto & 0,9811 & 1,78 & 1,80 & 1,75 & 0,7236 & 0,6122 & 1,71 & 1,84 & 0,1582 & 0,032 \\
\hline Patinho & 0,8823 & 3,76 & 3,59 & 3,69 & 0,5129 & 0,1469 & 3,63 & 3,74 & 0,2439 & 0,042 \\
\hline \multicolumn{11}{|l|}{ Classificação } \\
\hline Primeira $^{2}$ & 0,8783 & 26,16 & 25,88 & 26,45 & 0,5451 & 0,3081 & 25,91 & 26,41 & 0,4404 & 0,259 \\
\hline Segunda $^{3}$ & 0,1506 & 35,15 & 35,56 & 35,69 & 0,1622 & 0,6571 & 36,20 & 34,72 & 0,0036 & 0,203 \\
\hline Nobres $^{4}$ & 0,5792 & 13,82 & 13,64 & 13,89 & 0,7724 & 0,2809 & 13,54 & 14,03 & 0,5101 & 0,228 \\
\hline Churrasco $^{5}$ & 0,8105 & 34,87 & 35,43 & 35,27 & 0,5164 & 0,4860 & 34,75 & 35,62 & 0,4487 & 0,396 \\
\hline Total & 0,1156 & 77,92 & 78,44 & 78,91 & 0,0418 & 0,9346 & 78,52 & 78,32 & 0,8682 & 0,390 \\
\hline
\end{tabular}

${ }^{1}$ Alcatra + picanha + maminha; ${ }^{2}$ Todos os cortes do traseiro, exceto músculo e coxão duro $;{ }^{3}$ Todos os cortes do dianteiro + músculo do traseiro + coxão duro;

${ }^{4}$ Alcatra completa + contrafilé + filé mignon; ${ }^{5}$ Alcatra completa + contrafilé + ponta de peito + cupim + ponta de agulha; ${ }^{6}$ Probabilidade; ${ }^{7}$ Erro padrão 
Em razão dos cortes nobres se localizarem na parte posterior da carcaça, um maior peso e rendimento de traseiro na carcaça são desejáveis pelo maior valor comercial (RODRIGUES FILHO et al., 2013). No entanto, ainda são praticadas penalizações nos preços pagos pelos frigoríficos ao produtor no abate de fêmeas, por volta de $8,0 \%$ a menos no preço da arroba em relação à cotação dos machos, devido às diferenças de peso da carcaça. Para os frigoríficos, o rendimento de carcaça e os pesos dos cortes comerciais, principalmente do traseiro, são medidas que interessam economicamente por serem mais rentáveis nas indústrias frigorífica e varejista de carnes (PASCOAL et al., 2011). Nesse aspecto, descontos nos preços pagos pela arroba de fêmeas poderiam ser considerados injustos, já que não foram observadas diferenças para rendimentos de carcaça e de cortes cárneos de maior valor comercial entre machos castrados e fêmeas Nelore x Canchim.

A adição de até $5,2 \%$ de óleo de linhaça na MS da dieta de bovinos cruzados aumenta o peso dos principais cortes cárneos do traseiro (Tabela 3 ), reduz as perdas no resfriamento da carcaça e não altera o teor de gordura renal-pélvicainguinal (Tabela 2).

A caracterização do conjunto de dados utilizados para as análises de correlações de Pearson são apresentados na Tabela 5. Para a análise das correlações os resultados foram considerados de baixa magnitude com valores até 0,39 ; moderada de 0,40 a 0,59 e alta acima de 0,60 (Tabela 6). Foram encontradas correlações significativas para todas as medidas corporais e variáveis estudadas, exceto para o comprimento e a espessura de gordura de cobertura na carcaça (Tabela $6)$.
Muitos estudos de correlações com medidas corporais foram realizados com o intuito de encontrar a melhor medida que se correlacionasse com o peso corporal do animal e/ou com características da carcaça. Nessa busca, muitos observaram correlações do perímetro torácico com o peso corporal e/ou peso da carcaça quente (ABDELHADI \& BABIKER, 2009; FERNANDES et al., 2010; CYRILLO et al., 2012), confirmando a importância desse tipo de estudo.

Uma vez que as medidas de altura do tórax, perímetro torácico e contorno pelviano foram as que se correlacionaram com o maior número de variáveis analisadas (Tabela 6), essas mensurações se revelaram importantes para a determinação dos melhores animais para produção de carne, por apresentarem maior correlação com características de produção e esses resultados evidenciam a importância de outras medições que, além do perímetro, podem ser utilizadas como ferramentas para predição de peso corporal e peso da carcaça em bovinos.

Dentre as medidas corporais, o contorno pelviano se sobressaiu por ter sido associado com o peso e rendimento de carcaça quente, assim como com o peso do traseiro especial. Além disso, o contorno pelviano apresentou a maior correlação com o traseiro e com os cortes nobres (Tabela 6). Como o rendimento de carcaça e o peso de abate são ainda as principais formas de comercialização no Brasil (GOMIDE et al., 2006), essa medida poderia auxiliar na estimativa dos maiores valores pagos pela carcaça, antes mesmo de os animais serem abatidos. Outra correlação observada para o contorno pelviano foi com a AOL. O acompanhamento da medição do contorno pelviano nos animais pode ajudar na estimativa dessa variável que 
Rev. Bras. Saúde Prod. Anim., Salvador, v.16, n.4, p.850-864 out../dez.., 2015 http://www.rbspa.ufba.br ISSN 15199940

é intimamente relacionada com a quantidade de músculo na carcaça além de ser uma metodologia simples e que necessita apenas de uma fita métrica para ser realizada. A inclusão do contorno pelviano nos programas de melhoramento genético pode ser interessante quando utilizada em conjunto com as demais medições, como o perímetro torácico e medidas de altura, na identificação dos melhores animais para corte.

Tabela 5. Valores mínimo, máximo, média e desvio padrão das variáveis avaliadas para bovinos Nelore x Canchim, terminados em confinamento

\begin{tabular}{|c|c|c|c|}
\hline Variáveis & Mínimo & Máximo & Média \\
\hline Peso de abate, $\mathrm{kg}$ & 423,00 & 605,00 & $515,62 \pm 41,09$ \\
\hline \multicolumn{4}{|l|}{ Medidas corporais, $\mathrm{cm}$} \\
\hline Altura da cernelha & 131,00 & 146,00 & $138,62 \pm 4,74$ \\
\hline Altura do tórax & 63,00 & 74,00 & $68,34 \pm 2,74$ \\
\hline Altura da garupa & 136,00 & 151,00 & $143,57 \pm 4,67$ \\
\hline Largura do tórax & 38,50 & 48,00 & $43,47 \pm 2,30$ \\
\hline Largura dos ísquios & 24,00 & 32,00 & $27,53 \pm 1,65$ \\
\hline Largura da garupa & 46,00 & 57,00 & $50,05 \pm 2,56$ \\
\hline Perímetro torácico & 186,00 & 210,00 & $196,10 \pm 6,29$ \\
\hline Contorno pelviano & 106,00 & 137,50 & $120,38 \pm 6,81$ \\
\hline \multicolumn{4}{|l|}{ Carcaça } \\
\hline Peso da carcaça quente, $\mathrm{kg}$ & 238,80 & 346,60 & $295,16 \pm 25,91$ \\
\hline Rendimento da carcaça quente, $\%$ & 46,01 & 61,51 & $56,45 \pm 2,91$ \\
\hline Comprimento, $\mathrm{cm}$ & 122,00 & 139,00 & $131,45 \pm 3,70$ \\
\hline Profundidade, $\mathrm{cm}$ & 61,50 & 72,00 & $66,55 \pm 2,68$ \\
\hline Peso da carcaça fria, $\mathrm{kg}$ & 233,20 & 342,20 & $290,88 \pm 25,96$ \\
\hline Área de olho de lombo, $\mathrm{cm}^{2}$ & 62,13 & 104,85 & $80,64 \pm 11,17$ \\
\hline Área de olho de lombo, $\mathrm{cm}^{2} / 100 \mathrm{~kg}$ carcaça & 22,83 & 31,90 & $27,68 \pm 2,32$ \\
\hline Espessura de gordura de cobertura, $\mathrm{mm}$ & 3,89 & 30,02 & $11,10 \pm 5,00$ \\
\hline Peso do dianteiro, $\mathrm{kg}$ & 88,40 & 130,40 & $108,68 \pm 11,63$ \\
\hline Peso do traseiro especial, $\mathrm{kg}$ & 102,80 & 153,40 & $132,97 \pm 11,87$ \\
\hline Peso da ponta de agulha, $\mathrm{kg}$ & 42,00 & 61,00 & $49,23 \pm 4,15$ \\
\hline \multicolumn{4}{|l|}{ Classificação dos cortes, $\mathrm{kg}$} \\
\hline Primeira $^{1}$ & 32,10 & 43,75 & $38,30 \pm 2,94$ \\
\hline Segunda ${ }^{2}$ & 42,76 & 63,23 & $52,12 \pm 5,26$ \\
\hline Nobres $^{3}$ & 34,08 & 47,04 & $41,06 \pm 3,17$ \\
\hline Churrasco $^{4}$ & 44,66 & 61,15 & $51,80 \pm 4,05$ \\
\hline Total & 95,86 & 136,93 & $115,20 \pm 9,51$ \\
\hline
\end{tabular}

${ }^{1}$ Todos os cortes do traseiro, exceto músculo e coxão duro; ${ }^{2}$ Todos os cortes do dianteiro + músculo do traseiro + coxão duro; ${ }^{3}$ Alcatra completa + contrafilé + filé mignon; ${ }^{4}$ Alcatra completa + contrafilé + ponta de peito + cupim + ponta de agulha. 
Tabela 6. Coeficientes de correlação de Pearson de medidas corporais com características de peso, carcaça e cortes cárneos de bovinos Nelore $\mathrm{x}$ Canchim, terminados em confinamento

\begin{tabular}{|c|c|c|c|c|c|c|c|c|}
\hline Variáveis & $\begin{array}{c}\text { Altura } \\
\text { tórax }\end{array}$ & $\begin{array}{l}\text { Altura } \\
\text { garupa }\end{array}$ & $\begin{array}{c}\text { Altura } \\
\text { cernelha }\end{array}$ & $\begin{array}{l}\text { Largura } \\
\text { tórax }\end{array}$ & $\begin{array}{l}\text { Largura } \\
\text { ísquios }\end{array}$ & $\begin{array}{c}\text { Largura } \\
\text { garupa }\end{array}$ & $\begin{array}{c}\text { Perímetro } \\
\text { torácico }\end{array}$ & $\begin{array}{l}\text { Contorno } \\
\text { pelviano }\end{array}$ \\
\hline \multicolumn{9}{|l|}{ Peso } \\
\hline Final & $0,69^{\mathrm{a}}$ & $0,46^{\mathrm{b}}$ & 0,30 & $0,55^{\mathrm{a}}$ & $-0,02$ & 0,33 & $0,66^{\mathrm{a}}$ & $0,52^{\mathrm{a}}$ \\
\hline Carcaça Quente & $0,46^{\mathrm{b}}$ & 0,26 & 0,17 & $0,56^{\mathrm{a}}$ & 0,10 & $0,45^{\mathrm{b}}$ & $0,56^{\mathrm{a}}$ & $0,70^{\mathrm{a}}$ \\
\hline Carcaça Fria & $0,47^{\mathrm{a}}$ & 0,27 & 0,17 & $0,56^{\mathrm{a}}$ & 0,09 & $0,45^{\mathrm{b}}$ & $0,59^{\mathrm{a}}$ & $0,65^{\mathrm{a}}$ \\
\hline Dianteiro & $0,50^{\mathrm{a}}$ & 0,20 & 0,11 & $0,62^{\mathrm{a}}$ & 0,01 & $0,39^{\mathrm{b}}$ & $0,63^{\mathrm{a}}$ & $0,51^{\mathrm{a}}$ \\
\hline Traseiro Especial & 0,34 & 0,27 & 0,17 & $0,49^{\mathrm{a}}$ & 0,19 & $0,49^{\mathrm{a}}$ & $0,42^{\mathrm{b}}$ & $0,73^{\mathrm{a}}$ \\
\hline Ponta de Agulha & $0,56^{\mathrm{a}}$ & 0,26 & 0,20 & 0,36 & $-0,09$ & 0,25 & $0,69^{\mathrm{a}}$ & $0,38^{\mathrm{b}}$ \\
\hline \multicolumn{9}{|l|}{ Carcaça } \\
\hline Rendimento & $0,40^{\mathrm{b}}$ & 0,23 & 0,07 & $0,57^{\mathrm{a}}$ & 0,12 & $0,40^{\mathrm{b}}$ & $0,47^{\mathrm{a}}$ & $0,73^{\mathrm{a}}$ \\
\hline Comprimento & 0,28 & 0,23 & 0,10 & 0,33 & 0,28 & 0,17 & 0,31 & 0,26 \\
\hline Profundidade & $0,48^{\mathrm{a}}$ & $-0,03$ & $-0,11$ & 0,26 & $-0,04$ & 0,16 & $0,59^{\mathrm{a}}$ & $-0,21$ \\
\hline $\mathrm{AOL}$ & $-0,07$ & $-0,03$ & $-0,04$ & 0,36 & $0,43^{\mathrm{b}}$ & $0,37^{\mathrm{b}}$ & 0,08 & $0,65^{\mathrm{a}}$ \\
\hline AOL $100 \mathrm{~kg}$ de carcaça & $-0,48^{\mathrm{a}}$ & $-0,25$ & $-0,19$ & 0,01 & $0,50^{\mathrm{a}}$ & 0,11 & $-0,40^{\mathrm{b}}$ & 0,32 \\
\hline EGC & 0,11 & $-0,12$ & 0,22 & $-0,15$ & $-0,31$ & 0,02 & 0,16 & 0,08 \\
\hline \multicolumn{9}{|l|}{ Classificação } \\
\hline Primeira $^{1}$ & $0,41^{\mathrm{b}}$ & $0,46^{\mathrm{b}}$ & $0,37^{\mathrm{b}}$ & 0,35 & 0,05 & $0,42^{\mathrm{b}}$ & 0,31 & $0,65^{\mathrm{a}}$ \\
\hline Segunda $^{2}$ & $0,63^{\mathrm{a}}$ & $0,43^{\mathrm{b}}$ & 0,31 & $0,45^{\mathrm{b}}$ & $-0,07$ & 0,26 & $0,55^{\mathrm{a}}$ & $0,44^{\mathrm{b}}$ \\
\hline Nobres $^{3}$ & $0,41^{\mathrm{b}}$ & $0,46^{\mathrm{b}}$ & $0,37^{\mathrm{b}}$ & 0,35 & 0,05 & $0,42^{\mathrm{b}}$ & 0,31 & $0,65^{\mathrm{a}}$ \\
\hline Churrasco $^{4}$ & $0,58^{\mathrm{a}}$ & $0,42^{\mathrm{b}}$ & $0,42^{\mathrm{b}}$ & 0,34 & $-0,18$ & 0,29 & $0,59^{\mathrm{a}}$ & $0,51^{\mathrm{a}}$ \\
\hline Total & $0,60^{\mathrm{a}}$ & $0,46^{\mathrm{b}}$ & 0,35 & $0,45^{\mathrm{b}}$ & $-0,04$ & 0,36 & $0,56^{\mathrm{a}}$ & $0,57^{\mathrm{a}}$ \\
\hline
\end{tabular}

${ }^{\mathrm{a}}$ Significativo $(\mathrm{P}<0,01) ;{ }^{\mathrm{b}}$ Significativo $(\mathrm{P}<0,05)$

${ }^{1}$ Todos os cortes do traseiro, exceto músculo e coxão duro; ${ }^{2}$ Todos os cortes do dianteiro + músculo do traseiro + coxão duro; ${ }^{3}$ Alcatra completa + contrafilé + filé mignon; ${ }^{4}$ Alcatra completa + contrafilé + ponta de peito + cupim + ponta de agulha 
Rev. Bras. Saúde Prod. Anim., Salvador, v.16, n.4, p.850-864 out../dez.., 2015 http://www.rbspa.ufba.br ISSN 15199940

Os resultados obtidos foram importantes pelas correlações significativas entre mensurações corporais in vivo com peso de abate e rendimento da carcaça, parâmetros utilizados na cadeia produtiva da carne brasileira. Ao introduzir avaliações de medidas corporais em um sistema de produção de carne ou experimentação pode se formar lotes homogêneos que, juntamente com a avaliação do peso corporal, poderão auxiliar na escolha da época de abate dos animais. De modo geral, as medidas biométricas têm como vantagem o baixo custo das medições, mas podem sofrer limitações, pois essas devem ser precisas com a correta identificação e localização dos pontos de referência, observando alterações de posição ou postura do animal que possam modificar o tônus muscular.

A introdução do contorno pelviano e da altura do tórax em programas de melhoramento genético podem auxiliar produtores e melhoristas na compra e/ou formação de rebanhos destinados a produção de carne. A medida biométrica do contorno pelviano apresenta as melhores correlações com as características utilizadas na comercialização, como o peso de carcaça quente.

\section{REFERÊNCIAS}

ABDELHADI, O.M.A.; BABIKER, S.A. Prediction of zebu cattle live weight using live animal measurements. Livestock

Research for Rural Development, v.21, n.8, p.1-6, 2009.

BHATT, R.S.; SOREN, N.M.; TRIPATHI, M.K.; KARIM, S.A. Effects of different levels of coconut oil supplementation on performance, digestibility, rumen fermentation and carcass traits of Malpura lambs. Animal
Feed Science and Technology, v.164, n.1-2, p.29-37, 2011.

CONFEDERAÇÃO DA AGRICULTURA E PECUÁRIA DO BRASIL - CNA. Oferta de alimento pode triplicar em 10 anos. Disponível em:

$<$ http://www.canaldoprodutor.com.br/co municacao/noticias/oferta-de-alimentopode-triplicar-em-10-anos>. Acesso em: 25 set. 2013.

COUTINHO FILHO, J.L.V.; PERES, R.M.; JUSTO, C.L. Produção de carne de bovinos contemporâneos, machos e fêmeas, terminados em confinamento. Revista Brasileira de Zootecnia, v.35, n.5, p.2043-2049, 2006.

CYRILLO, J.N.S.G.; NARDON, R.F.; MERCADANTE, M.E.Z.; BONILHA, S.F.M.; ARNANDES, R.H.B. Relações entre medidas biométricas, características de carcaça e cortes cárneos comerciais em bovinos Zebu e Caracu. Boletim da Indústria Animal, v.69, n.1, p.71-77, 2012.

CYRILLO, J.N.S.G.; RAZOOK, A.G.; FIGUEIREDO, L.A.; BONILHA NETO, L.M.; MERCADANTE, M.E.Z.; TONHATI, H. Estimativas de tendências e parâmetros genéticos do peso padronizado aos 378 dias de idade, medidas corporais e perímetro escrotal de machos Nelore de Sertãozinho, SP.

Revista Brasileira de Zootecnia, v.30, n. 1, p.56-65, 2001.

ENGLE, T.E.; SPEARS, J.W.; ARMSTRONG, T.A.; WRIGHT, C.L.; ODLE, J. Effects of dietary cooper source and concentration on carcass characteristics and lipid and cholesterol metabolism in growing and finishing steers. Journal of Animal Science, v.78, n.3, p.1053-1059, 2000. 
Rev. Bras. Saúde Prod. Anim., Salvador, v.16, n.4, p.850-864 out../dez.., 2015 http://www.rbspa.ufba.br ISSN 15199940

FELÍCIO, P.E. de. Classificação, tipificação e qualidade da carne bovina. In: CONGRESSO BRASILEIRO DE CIÊNCIA E TECNOLOGIA DE CARNES, 6., 2011, São Pedro, Sp. Anais... São Pedro, Sp, 2011. p.127133.

FERNANDES, H.J.; TEDESCHI, L.O.; PAULINO, M.F.; PAIVA, L.M.

Determination of carcass and body fat compositions of grazing crossbred bulls using body measurements. Journal of Animal Science, v.88, n.4, p.14421453, 2010.

FISHER, A.V. The profile area of beef carcass and its relationship to carcass composition. Animal Production, v.20, p.355-361, 1975.

GEAY, Y.; BAUCHART, D.; HOCQUETTE, J.F.; CULIOLI, J. Effect of nutritional factors on biochemical, structural and metabolic characteristics of muscles in ruminants, consequences on dietetic value and sensorial qualities of meat.

\section{Reproduction Nutrition}

Development, v.41, n.1, p.1-26, 2001.

GOMIDE, L.A.M.; RAMOS, E.M.; FONTES, P.R. Tecnologia de abate e tipificação de carcaças. Viçosa, MG: Universidade Federal de Viçosa, 2006. 370p.

KUSS, F., RESTLE, J., BRONDANI, I.L., PACHECO, P.S., SILVEIRA, M.F., PAZDIORA, R.D., CEZIMBRA, I.M. Órgãos vitais e trato gastrointestinal de vacas de descarte mestiças Charolês x Nelore abatidas com pesos distintos. Revista Brasileira de Zootecnia, v.36, n.2, p.421-429, 2007.
LANNA, D.P.D.; BARIONI, L.G.; TEDESCHI, L.O.; BOIN, C.RLM 2.0 Ração de Lucro Máximo. Versão 2.0. Piracicaba, SP: Esalq, Departamento de Zootecnia, 1999.

LAWRIE, R.A. Ciência da carne. 6 ed. Porto Alegre: Artmed, 2005. 384p.

MINISTÉRIO DA AGRICULTURA, PECUÁRIA E ABASTECIMENTO MAPA. Projeções do Agronegócio. Brasil 2012/2013 a 2022/2023.

Assessoria de Gestão Estratégica Brasília: Mapa/ACS, 2013. 96p.

Disponível em:

$<$ http://www.agricultura.gov.br/arq editor $/$ projecoes\%20-

20versao\%20atualizada.pdf $>$. Acesso em: 25 set. 2013.

MARTIN, C.A.; ALMEIDA, V.V.; RUIZ, M.R.; VISENTAINER, J.E.L.; MATSHUSHITA, M.; SOUZA, N.E.; VISENTAINER, E J.V. Ácidos graxos poli-insaturados omega-3 e omega-6: importância e ocorrência em alimentos. Revista de Nutrição, v.19, n.6, p.761770, 2006.

McDONALD, L.E.; PINEDA, M.H. Endocrinologia Veterinaria y Reproducción. 4ed. México: Interamericana/ McGrow-Hill, 1991. $216 p$.

OWENS, F.N.; GILL, D.R.; SECRIST, D.S.; COLEMAN, S.W. Review of some aspects of growth and development of feedlot cattle. Journal of Animal Science, v.73, p.3152-3172, 1995.

PASCOAL, L.L.; VAZ. F.N.; VAZ, R.Z.; RESTLE, J.; PACHECO, P.S.; SANTOS, J.P.A. Relações comerciais entre produtor, indústria e varejo e as implicações na diferenciação e precificação de carne e produtos bovinos não-carcaça. Revista Brasileira de Zootecnia, v.40, p.82-92, 2011. Supl. Especial. 
Rev. Bras. Saúde Prod. Anim., Salvador, v.16, n.4, p.850-864 out../dez.., 2015 http://www.rbspa.ufba.br ISSN 15199940

PAZDIORA, R.D. Peso de abate e ureia protegida na dieta de terminação em confinamento de bovinos Nelore não castrados. 2011. 125p. Tese (Doutorado em Zootecnia) - Faculdade de Ciências Agrárias e Veterinárias, Universidade Estadual Paulista, Jaboticabal.

RODRIGUES FILHO, M.; ANDRADE, I.F.; LADEIRA, M.M.; RODRIGUES, N.E.B.; LOPES, L.S. Características de carcaça e cortes comerciais de tourinhos Red Norte suplementados com óleos de fritura e soja terminados em confinamento. Revista Brasileira de Saúde e Produção Animal, [online] v.14, n.1, p.54-66, 2013.

ROSA, B.L. Óleo de linhaça na dieta de fêmeas e machos castrados Nelore x Canchim, terminados em confinamento. 2014. 72p. Tese (Doutorado em Zootecnia) - Faculdade de Ciências Agrárias e Veterinárias, Universidade Estadual Paulista, Jaboticabal.

SAMPAIO, N.S. Estudos das regiões corporais dos bovinos de importância nos julgamentos. In: PEIXOTO, A.M.; MOURA, J.C.; FARIA, V.P. (Eds.). Exterior e julgamento de bovinos. Piracicaba: FEALQ, 1990. p.15-38.

SAS - Statistical Analysis System. 9.2. User's guide. Cary: NC: SAS Institute Inc., 2009.

SILVA, F.V.; ROCHA JÚNIOR, V.R.; BARROS, R.C.; PIRES, D.A.A.; MENEZES, G.C.C.; CALDEIRA, L.A. Ganho de peso e características de carcaça de bovinos Nelore castrados ou não-castrados terminados em confinamento. Revista Brasileira de Zootecnia, v.37, n.12, p.2199-2205, 2008.
TULLIO, R.R. Estratégias de manejo para produção intensiva de bovinos visando à qualidade da carne. 2004. 107p. Tese (Doutorado em Zootecnia) Faculdade de Ciências Agrárias e Veterinárias, Universidade Estadual Paulista, Jaboticabal.

VANDER POL, K.J.; LUEBBE, M.K.; CRAWFORD, G.I.; ERICKSON, G.E.; KLOPFENSTEIN, T.J. Performance and digestibility characteristics of finishing diets containing distillers grains, composites of corn processing coproducts, or supplemental corn oil.

Journal of Animal Science, v.87, n.2, p.639-652, 2009.

YOKOO, M.J.I.; ORTELAN, A.A.; SARMENTO, J.L.R.; ALBUQUERQUE, L.G.; RESENDE, K.T.; REIS, R.A.; TEIXEIRA, I.A.M.A.; ROSA, G.J.M. Estudo de características de crescimento e de carcaça medidas por ultra-sonografia em novilhas de dois grupos genéticos. Ciência Animal Brasileira, v.9, n.4, p.948-957, 2008.

Data de recebimento: 29/09/2014

Data de aprovação: 09/11/2015 